\title{
The Lethal Effects of Cytokine-induced Nitric Oxide on Cardiac Myocytes Are Blocked by Nitric Oxide Synthase Antagonism or Transforming Growth Factor $\boldsymbol{\beta}$
}

David J. Pinsky, Bolin Cai, Xiaochun Yang, Carlos Rodriguez, Robert R. Sciacca, and Paul J. Cannon

Department of Medicine, Columbia University College of Physicians and Surgeons, New York 10032

\begin{abstract}
Inducible nitric oxide (NO) produced by macrophages is cytotoxic to invading organisms and has an important role in host defense. Recent studies have demonstrated inducible NO production within the heart, and that cytokine-induced NO mediates alterations in cardiac contractility, but the cytotoxic potential of nitric oxide with respect to the heart has not been defined. To evaluate the role of inducible nitric oxide synthase (iNOS) on cardiac myocyte cytotoxicity, we exposed adult rat cardiac myocytes to either cytokines alone or to activated $\mathbf{J 7 7 4}$ macrophages in coculture. Increased expression of both iNOS message and protein was seen in J774 macrophages treated with IFN $\gamma$ and LPS and cardiac myocytes treated with TNF- $\alpha$, IL-1 $\beta$, and IFN $\gamma$. Increased NO synthesis was confirmed in both the coculture and isolated myocyte preparations by increased nitrite production. Increased NO synthesis was associated with a parallel increase in myocyte death as measured by CPK release into the culture medium as well as by loss of membrane integrity, visualized by trypan blue staining. Addition of the competitive NO synthase inhibitor L-NMMA to the culture medium prevented both the increased nitrite production and the cytotoxicity observed after cytokine treatment in both the isolated myocyte and the coculture experiments. Because transforming growth-factor beta modulates iNOS expression in other cell types, we evaluated its effects on cardiac myocyte iNOS expression and NO-mediated myocyte cytotoxicity. TGF- $\beta$ reduced expression of cardiac myocyte iNOS message and protein, reduced nitrite production, and reduced NO-mediated cytotoxicity in parallel. Taken together, these experiments show the cytotoxic potential of endogenous NO production within the heart, and suggest a role for TGF- $\beta$ or NO synthase antagonists to mute these lethal effects. These findings may help explain the cardiac response to sepsis or allograft rejection, as well as the progression of dilated cardiomyopathies of diverse etiologies. (J. Clin. Invest. 1995. 677-685.) Key words: cardiac myocytes $\bullet$ cytokines $\bullet$ nitric oxide $\bullet$ autotoxicity $\bullet$ transforming growth factor $\beta$
\end{abstract}

\section{Introduction}

Immune mechanisms are being increasingly recognized as pathophysiologic mediators in a number of cardiac diseases (1,

Address correspondence to Dr. David Pinsky, Columbia University, College of Physicians and Surgeons, P\&S 11-518, 630 W. 168th St., New York, NY 10032. Phone: 212-305-1615; FAX: 212-305-5337. Received for publication 22 July 1994.

J. Clin. Invest.

(c) The American Society for Clinical Investigation, Inc.

0021-9738/95/02/0677/09 \$2.00

Volume 95, February 1995, 677-685
2). Proinflammatory cytokines are released locally in a variety of conditions associated with myocardial inflammation, including cardiac allograft rejection, myocardial infarction, myocarditis, and idiopathic cardiomyopathies (1-3). In addition, elevated levels of circulating cytokines have been described in advanced heart failure $(4,5)$. Because cytokines are potent inducers of nitric oxide synthesis in macrophages $(6-11)$, smooth muscle cells $(12-15)$, endothelial cells $(9-11,16,17)$, and cardiac myocytes (18), we investigated whether local production of nitric oxide by infiltrating macrophages and by cytokine-stimulated cardiac myocytes may be involved in the myocardial necrosis which often accompanies myocardial inflammation.

Nitric oxide is synthesized from the amino acid L-arginine by a family of enzymes, nitric oxide synthases (NOS) ${ }^{1}$ (14). The constitutive isoform of NOS found in endothelial cells produces tiny puffs of NO, which serves as an important regulator of vasomotor tone, platelet aggregation, and neutrophil adhesivity to the vascular wall $(9-11)$. The constitutive isoform of NOS found in brain and in non-adrenergic noncholinergic neurons produces small amounts of NO which acts as a neurotransmitter (11). In contrast, the cytokine-inducible isoform of NOS (iNOS) produces large quantities of NO over prolonged periods, and plays an important role in cells of monocyte/macrophage lineage, to defend the host against invading microorganisms $(6-8,19)$. iNOS expression may not be entirely benign for the host organism or adjacent cells, however. Cytotoxic effects of large amounts of NO produced by iNOS in adjacent cells have been reported in tumor cells (20-22), pancreatic islet cells $(23-25)$, neural cells $(26,27)$, ovarian epithelial cells $(28)$, and hepatocytes (29). In the cardiovascular system, NO produced by iNOS is a major pathophysiologic mediator of septic shock (9-11), and has been shown to mediate in large part the negative inotropic effects of cytokines (30-33). Although these effects of NO to inhibit myocyte contractility are well substantiated, and may mediate the negative inotropy observed in states such as sepsis (34) and cardiac transplant rejection (35), the role of NO in myocyte killing remains speculative. Understanding the potentially lethal effects of NO on cardiac myocytes is important because not only are tissue-based macrophages and monocytes abundant within the heart, especially after infarction (36) and during periods of inflammation $(1,2,37)$ and allograft rejection $(35,38-40)$, but a cytokine-inducible NO synthase within cardiac myocytes themselves could serve as an endogenous high-output pathway for NO synthesis $(18,41-43)$.

Accordingly, the present study was designed to test two hypotheses, that $(a)$ NO produced by iNOS in activated macrophages can be lethal to adjacent adult cardiac myocytes, and (b) proinflammatory cytokines can induce iNOS expression in

1. Abbreviations used in this paper: CPK, creatine phosphokinase; iNOS, inducible isoform of NOS; NOS, nitric oxide synthase. 
adult cardiac myocytes, and that NO so produced can be autotoxic to the cardiac myocytes. This study confirms these hypotheses, and may have important implications with respect to the pathophysiology of a broad range of inflammatory cardiac diseases, as well as to the pathogenesis of dilated cardiomyopathy.

\section{Methods}

Isolation of adult rat ventricular myocytes. Isolation and preparation of adult rat ventricular myocytes was based on a modification of previously described techniques $(44,45)$. Male Wistar-Furth rats $(250-300 \mathrm{~g})$ were anesthetized and heparinized $(1500 \mathrm{U} / \mathrm{kg})$, after which their hearts were rapidly excised and placed in cold nominally calcium-free buffer. In aseptic fashion, perfusate was introduced into the cross-clamped aortic root at a constant rate (3-4 $\mathrm{ml} / \mathrm{min}$ ) using a Langendorff-type apparatus. An oxygenated, calcium-free perfusate was infused for the initial $5 \mathrm{~min}$ $\left(\mathrm{NaCl} 111 \mathrm{mM}, \mathrm{KCl} 5.4 \mathrm{mM}, \mathrm{NaH}_{2} \mathrm{PO}_{4} 1.5 \mathrm{mM}, \mathrm{MgCl}_{2} 1.6 \mathrm{mM}\right.$ $\mathrm{NaHCO}_{3} 4.2 \mathrm{mM}$, Hepes $20 \mathrm{mM}$, glucose $5.4 \mathrm{mM}$, L-glutamine $4.1 \mathrm{mM}$, and taurine $10 \mathrm{mM}$ ) (Sigma Chemical Co., St. Louis, MO), dissolved in MEM with MEM amino acid and vitamin supplement (GIBCO BRL, Grand Island, NY). After this initial perfusion was completed, collagenase B (final concentration $0.055 \%$; Boehringer-Mannheim, Indianapolis, IN) was added and recirculating perfusion continued at $35^{\circ} \mathrm{C}$ for 25 $\min$. The ventricles were minced and then placed into $10 \mathrm{ml}$ of a digestion solution consisting of the base perfusion solution described above, to which $11 \mathrm{mg}$ collagenase $\mathrm{B}, \mathrm{CaCl}_{2}$ (final concentration $0.6 \mathrm{mM}$ ) and bovine serum albumin $(5 \mathrm{gm} / \mathrm{l})$ were added. The tissue was placed in a $33^{\circ} \mathrm{C}$ shaker, and every $15 \mathrm{~min}$, the myocyte-rich solution was decanted and new digestion solution was added. This process was repeated 5-6 times. The decanted fractions were filtered through an autoclaved nylon mesh, pooled, and then subjected to percoll-density gradient centrifugation (46) (Sigma Chemical Co.). Myocytes sedimenting at the 1.082/ $1.062 \mathrm{~g} / \mathrm{ml}$ interface were collected, washed 3 times, and resuspended in DME with $10 \%$ fetal bovine serum (Gemini Bioproducts, Calabasas, CA), $1 \%$ penicillin/streptomycin and $1 \%$ L-glutamine, and were plated on plasticware precoated with laminin $(60 \mu \mathrm{g}$ per $100-\mathrm{mm}$ dish for the Northern and Western blots, and $3.52 \mu \mathrm{g}$ per well for 24-well plates; Sigma Chemical Co.). The medium was changed after $2 \mathrm{~h}$ to remove cellular debris and contaminating cells.

Preparation of J774.A1 macrophages. Mouse J774.A1 cells of the monocyte/macrophage line (American Type Culture Collection, Rockville, MD) were cultured in a stirrer flask in DME with $10 \%$ fetal bovine serum, $2 \mathrm{mM}$ L-glutamine, $50 \mu \mathrm{g} / \mathrm{ml}$ penicillin, and $50 \mu \mathrm{g} / \mathrm{ml}$ streptomycin, and maintained at a cell density of $4-8 \times 10^{5}$ cells $/ \mathrm{ml}$ by subculturing every $2-3 \mathrm{~d}(47)$. For the coculture experiments, cells were plated on transwell plates ( $9 \mathrm{~mm}$ diameter, $45 \mu \mathrm{m}$ pore size; Fisher Scientific, Pittsburgh, PA) at a density of $4.0 \times 10^{5}$ cells/well. For preparation of the Northern and Western blots, they were plated at a similar density on $100-\mathrm{mm}$ tissue culture dishes. After $24 \mathrm{~h}$, they were stimulated with IFN $\gamma(100 \mathrm{U} / \mathrm{ml})$ and lipopolysaccharide $(5 \mu \mathrm{g} / \mathrm{ml})$ for an additional $24 \mathrm{~h}$, or left unstimulated as indicated.

Myocyte/macrophage coculture experiments. Medium was changed in the 24-well myocyte plates $24 \mathrm{~h}$ after harvest, after which transwell inserts containing the $\mathbf{J} 774$ cells macrophages (prepared as described above) were placed over the myocyte lawn. After a 24-h period of coculture, the transwell inserts were removed and indices of myocyte death measured as described below.

Measurement of myocyte death. Viability of ventricular myocytes was measured in two ways. Creatine phosphokinase (CPK) extruded into the supernatant was measured using a commercially available colorimetric assay (Sigma Chemical Co.). Its specificity for myocytes in the experimental system was confirmed by the virtually unmeasurable CPK levels in the supernatant of cytokine stimulated $\mathrm{J} 774$ cells maintained in the absence of myocytes, even after killing of the J774 cells with alcohol or freezing and thawing. After a 100- $\mu$ l aliquot of supernatant was removed for CPK assay, sodium hydroxide $(0.1 \mathrm{~N})$ was added to each well, and protein content was determined by the method of Lowry et al. (48). CPK values (units/liter) were divided by the protein content $(\mathrm{mg} / \mathrm{ml})$ of each well to normalize for spurious variations in cell plating density. The ability of cardiac myocytes to exclude trypan blue was used as an index of membrane integrity, and was quantified by counting one hundred cells per well in a 24 -well plate, with percent viability being defined as the percentage of cells that excluded trypan blue. Nitrite was measured in $100-\mu \mathrm{l}$ aliquots of supernatant from wells just prior to trypan blue staining, using the Griess reagent and measuring absorbance at $550 \mathrm{~nm}$ as described (49). Sodium nitrite (Sigma Chemical Co.) served as the standard for these experiments.

Cytokine, LNMMA, and TGF- $\beta$ exposure. $24 \mathrm{~h}$ after primary culture of the myocytes (at the time of medium change), supplemental L-arginine $(2 \mathrm{mM})$ was added in all experiments. At this same time, L-NMMA (10 mM; Calbiochem Corp., La Jolla, CA), and/or cytokines were added as indicated in the text. The added cytokines included recombinant human TNF- $\alpha$ ( $25 \mathrm{ng} / \mathrm{ml}$; Genzyme, Cambridge, MA), IL-1- $\beta$ (5 ng/ $\mathrm{ml}$; Genzyme), and IFN- $\gamma$ (100 U/ml; Genzyme), and/or transforming growth factor $B_{1}$ (recombinant human, $5 \mathrm{ng} / \mathrm{ml}$; Genzyme). In all instances, the $\mathrm{pH}$ of the medium was adjusted to 7.4 .

Northern analysis for iNOS. Poly(A) RNA was isolated from $\mathrm{J} 774$ macrophages or ventricular myocytes by oligo (dT) cellulose adsorption (Fast TrackTM RNA isolation kit k1593-02; Invitrogen, SanDiego, CA) (50). Equal amounts of poly(A) mRNA $(1.2 \mu \mathrm{g})$ were electrophoresed in a $1 \%$ agarose formaldehyde gel, and then blotted by capillary transfer to nitrocellulose membranes. The blots were prehybridized for $6-8 \mathrm{~h}$ at $42^{\circ} \mathrm{C}$ in formamide $(50 \%)$, SDS $(0.1 \%)$, standard saline citrate $(2 \times)$, Denhardt's solution $(2 \times)$, denatured salmon testes DNA $(0.125 \mathrm{mg} / \mathrm{ml})$, and EDTA $(1 \mathrm{mM})(\mathrm{pH} 7.4)$. Hybridization was carried out at $42^{\circ} \mathrm{C}$ for 12-18 h with a murine iNOS probe generously provided by Dr. C. Nathan (Cornell University Medical College, New York, NY), and labeled with $\left.{ }^{32} \mathrm{P}\right]-\mathrm{dCTP}$ to a specific activity of $1 \times 10^{6} \mathrm{cpm} / \mu \mathrm{g}$ of cDNA using a random primer labeling kit (Amersham Corp., Arlington Heights, IL), followed by washing under increasingly stringent conditions. Blots were then exposed to XAR-5 film (Eastman Kodak Co., Rochester, NY) with DuPont (Wilmington, DE) Cronex Lightening Plus intensifying screens at $-70^{\circ} \mathrm{C}$ for 3-7 d. Human GAPDH cDNA labeled with $\left[{ }^{32} \mathrm{P}\right]-$ dCTP was used in a second hybridization to confirm equal loading of each lane. Blots of freshly prepared samples were performed four times to confirm initial results.

Western analysis for iNOS. $\mathrm{J} 774$ cells or cardiac myocytes were lysed in a lysis buffer containing $150 \mathrm{mM} \mathrm{NaCl}, 1.0 \% \mathrm{NP}-40,0.1 \%$ SDS, $1 \mathrm{mM}$ EDTA, and $50 \mathrm{mM}$ Tris (pH 7.7), supplemented with protease inhibitors $(10 \mu \mathrm{g} / \mathrm{ml}$ of antipain and leupeptin, and $1 \mathrm{mM}$ PMSF), and centrifuged at $10,000 \mathrm{rpm}$ for $20 \mathrm{~min}$ at $4^{\circ} \mathrm{C}$. The cytosolic proteins $(15 \mu \mathrm{g} / \mathrm{lane})$ were electrophoresed on an $8 \%$ SDS-polyacrylamide gel, transferred to a nitrocellulose filter, and then immunoblotted with rabbit polyclonal antiserum raised against the amino acid 117128 sequence of the (mouse) macrophage-inducible NO synthase (generously provided by Dr. D. Harrison, Emory University, Atlanta, GA) at a 1:1,000 dilution. Anti-rabbit horseradish peroxidase-conjugated antibody was used as a secondary antibody. Blots were detected with the enhanced chemiluminescence method (Amersham Corp.). Blots of freshly prepared samples were performed three times to confirm initial results.

Statistics. All experiments related to myocyte cytotoxicity (including the coculture experiments, the isolated myocyte/cytokine experiments, and the isolated myocyte/TGF- $\beta$ experiments) were performed using a minimum of 3-5 wells per condition for each myocyte preparation. The coculture experiments were repeated on four separate occasions, and the isolated myocyte and myocyte/TGF- $\beta$ experiments were each repeated three times on different weeks to ensure that the results were myocyte batch independent. Data were analyzed by repeated measures analysis of variance. Post hoc tests of the significance of differences among individual means were performed using Tukey's procedure. Significance was established if $P<0.05$.

\section{Results}

Because histologic examination of rejecting cardiac allografts often shows macrophages adjacent to dying myocytes $(35,38)$, 


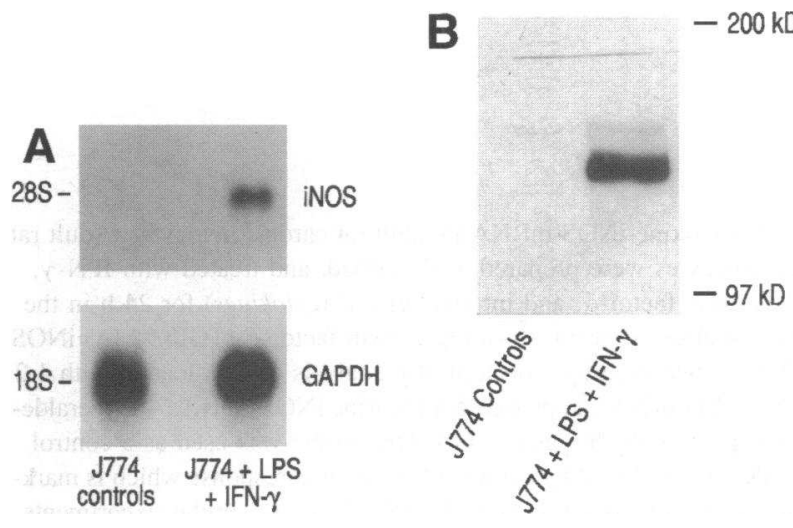

Figure 1. Effect of cytokines on expression of iNOS in $\mathrm{J} 774$ macrophages. (A) Macrophage iNOS polyadenylated mRNA was extracted and Northern blotting performed. IFN- $\gamma$ and LPS induce iNOS transcripts in J774 macrophages, whereas these transcripts are not observed in controls. $(B)$ In similar experiments, Western blots demonstrate that IFN- $\gamma$ and LPS induce iNOS expression in $\mathbf{J} 774$ macrophages. iNOS protein is undetectable in untreated controls.

experiments were designed to ascertain whether the inducible nitric oxide synthase expressed by activated J774.A1 macrophages was able to kill adjacent myocytes. As IFN- $\gamma$ and LPS are potent inducers of iNOS in macrophages $(6,51)$. we first demonstrated that iNOS was induced in $\mathbf{J} 774$ macrophages under the conditions employed for coculture experiments with cardiac myocytes. Stimulation of J774 macrophages with IFN$\gamma$ and LPS induced both iNOS message (Fig. $1 A$ ) and protein (Fig. $1 B$ ). In addition, iNOS enzyme activity (quantified by measuring nitrite, an oxidation product of NOS (49), was increased by the same protocol of IFN- $\gamma$ and LPS treatment. and was blocked by addition of a fivefold molar excess of the competitive NO synthase antagonist L-NMMA (Fig. 2 A). To test whether NO produced by stimulated macrophages was toxic to adjacent cardiac myocytes, both stimulated or unstimulated J774 macrophages plated on transwell inserts were placed over a lawn of adult rat cardiac myocytes. CPK release and trypan blue exclusion, measured as indices of myocyte death, were not significantly different between control myocytes and those cocultured with unstimulated macrophages (Fig. 2, $B$ and $C$ ).
However, when the macrophages were stimulated with lipopolysaccharide and IFN $\gamma$, myocyte death was $43 \%$ greater than controls $(P<0.05$; Fig. $2 B)$, and CPK release was $151 \%$ greater than controls $(P<0.05 ;$ Fig. $2 C)$. Evidence indicating that the diffusible mediator produced by stimulated macrophages which killed adjacent myocytes was NO included the parallel increases in nitrite production. CPK release, and myocyte death (Fig. $2 A$ ), as well as the coincident inhibition of NO production and cytotoxicity by L-NMMA (Fig. 2, $A-C$ ).

Because inducible NO synthase activity has been reported in cardiac myocytes $(18,41-43)$, it was important to exclude a role for myocyte-derived $\mathrm{NO}$ as the cytotoxic agent in the coculture experiments. Myocytes which were plated in the absence of macrophages and stimulated with the identical concentrations of lipopolysaccharide and IFN $\gamma$ failed to produce more nitrite than unstimulated myocytes $(4.0 \pm 0.2$ vs. $4.8 \pm 0.3 \mu \mathrm{M}$, respectively, $P=\mathrm{NS}$ ). This result indicates that the source of the increased NO production in the coculture experiments was the $\mathrm{J} 774$ macrophages.

Although the combination of lipopolysaccharide and IFN $\gamma$
A

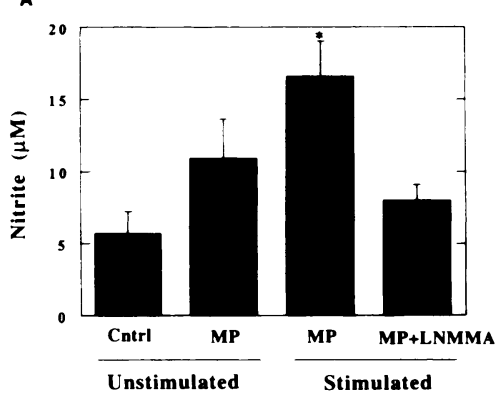

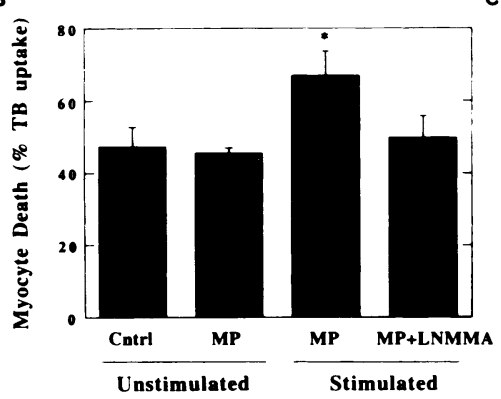

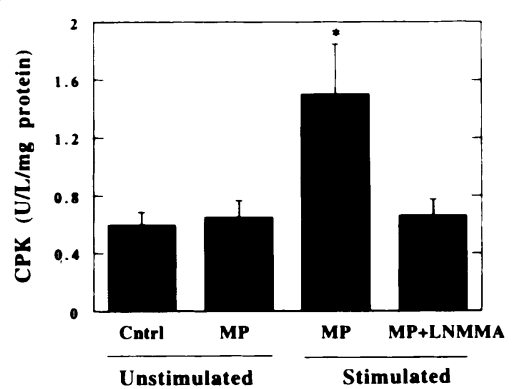

Figure 2. $\mathrm{J} 774$ macrophage/adult rat cardiac myocyte coculture experiments. $(A)$ Nitric oxide production measured by detecting its oxidation product (nitrite) in the culture supernatant. Macrophages (MP) were either treated with LPS and IFN for $24 \mathrm{~h}$ (Stimulated) or untreated (Unstimulated), and nitrite production measured using the Griess reaction. Nitrite levels are elevated in the coculture medium after LPS and IFN- $\gamma$ treatment, with this production inhibited by the competitive nitric oxide synthase inhibitor L-N ${ }^{\mathrm{G}}$-monomethyl-L-arginine (L-NMMA). Because LPS and IFN- $\gamma$ do not cause myocyte nitrite release (see Results), this increase can be attributed to the macrophages in coculture, and corresponds to the induction of iNOS message and protein (Fig. 1). (B) Myocyte death quantified by loss of membrane integrity after 24 h of coculture, indicated by trypan blue staining. After removal of the transwell insert in which macrophages had been plated, 100 myocytes on each ventricular lawn were counted, and percent death expressed as $100 \times$ the number of stained cells/total number of cells. Increased cell death was noted only following LPS and IFN- $\gamma$ treatment in the absence of L-NMMA, and corresponds to macrophage NO synthesis. $(C)$ CPK was measured as another index of myocyte death (macrophages released only trace amounts of CPK. see methods section), and normalized to myocyte protein concentration for each well. CPK release is increased only following LPS and IFN- $\gamma$ treatment in coculture in the absence of L-NMMA. Experiments for $A-C$ were performed in 24-well tissue culture dishes and represent data from experiments performed on four separate weeks, analyzed by repeated measures ANOVA $(* P$ $<0.05$ vs. unstimulated control cocultures). 

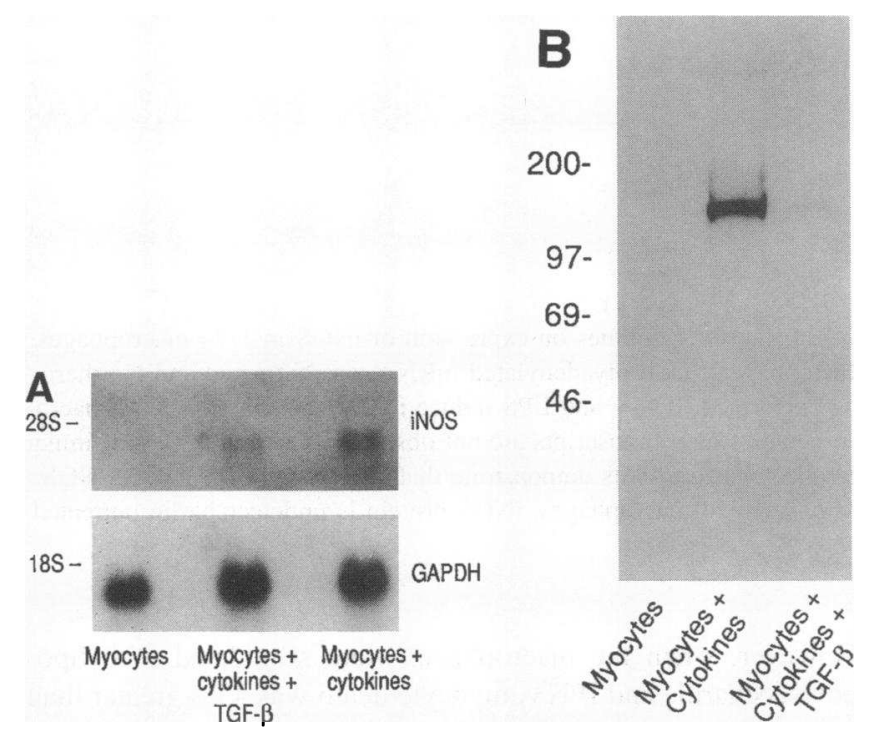

clearly induced iNOS expression in the $\mathrm{J} 774$ cells, it failed to induce NO synthesis in purified adult rat ventricular myocytes. It has been reported that there is increased iNOS activity in neonatal rat cardiac myocytes treated with IL- $1 \beta(18,43)$ and adult rat cardiac myocytes treated with TNF- $\alpha$ and IL- $1 \beta$ (41). In addition, IFN- $\gamma$ synergizes with TNF to induce NOS activity in vascular smooth muscle cells (15). Accordingly, experiments were designed using identical adult myocyte preparations as in the coculture experiments, but exposed for $24 \mathrm{~h}$ to a triple cytokine combination consisting of IFN $\gamma$, TNF- $\alpha$, and IL- $1 \beta$ in the absence of $\mathrm{J} 774$ cells. After this treatment, Northern blotting using a macrophage iNOS cDNA probe revealed a single strong band (Fig. $3 \mathrm{~A}$, right lane) migrating in a position similar to that seen in stimulated $\mathbf{J} 774$ cells (Fig. $1 A$ ). This band was completely absent in untreated control myocytes (Fig. 3 A, left lane). Western blotting confirmed the induction of iNOS protein in purified adult rat ventricular myocytes stimulated with the same triple cytokine combination (Fig. $3 \mathrm{~B}$, middle lane), and there were also corresponding increases in iNOS enzyme activity (Fig. $4 \mathrm{~A}$ ).

To establish whether cardiac myocyte iNOS may have an autotoxic role in cardiac myocytes exposed to cytokines, we evaluated cardiac myocyte death as described above for the coculture experiments. Cardiac myocytes stimulated with this triple cytokine combination released more nitrite and had $89 \%$ more CPK release $(P<0.05)$ and a greater percentage of dead cells at $24 \mathrm{~h}$ compared with unstimulated myocytes $(59 \pm 2.3 \%$ vs. $38 \pm 1.5 \%, P<0.05$; Fig. $4, B$ and $C$ ). As in the coculture experiments. L-NMMA inhibited the increased nitrite release and was completely protective against cytokine-induced cell death, with changes in nitrite release paralleling myocyte death in all instances (Fig. $4 A$ ). Representative trypan blue staining of myocytes is shown in (Fig. 5). It can be seen that living myocytes had a characteristic rod-shaped/striated appearance at $24 \mathrm{~h}$ (45). Although there is a background level of cell death at $24 \mathrm{~h}$ in all experiments, treatment with cytokines caused a marked increase in cell death (loss of membrane integrity resulting in the uptake of trypan blue), which was largely prevented by cotreatment with L-NMMA (Fig. 5).

As inducible NO synthase activity is not subject to calcium-
Figure 3. Cytokine-iNOS mRNA in adult rat cardiac myocytes. Adult rat cardiac myocytes were prepared as described, and treated with IFN- $\gamma$, tumor necrosis factor- $\alpha$, and interleukin 1- $\beta$ (cytokines) for $24 \mathrm{~h}$ in the presence or absence of transforming growth factor- $\beta$ (TGF- $\beta$ ). ( $A$ ) iNOS mRNA was measured by Northern blot analysis of gels loaded with 1.2 $\mu \mathrm{g}$ of poly(A) mRNA and probed with murine iNOS cDNA. A glyceraldehyde phosphate dehydrogenase (GAPDH) probe was used as a control. iNOS mRNA is induced by cytokine treatment, a response which is markedly attenuated by cotreatment with TGF- $\beta$. $(B)$ In similar experiments, iNOS expression in adult rat ventricular myocytes was measured by Western blot, using a rabbit polyclonal anti-murine iNOS as the primary antibody. iNOS protein expression is induced by cytokine treatment. Cotreatment with TGF- $\beta$ markedly reduces the expression of iNOS protein. Northern and Western blots were repeated on three occasions to confirm results.

dependent regulation $(6,14)$, we investigated whether inhibiting iNOS expression might prevent NO-mediated autotoxicity. Because transforming growth factor- $\beta$ (TGF- $\beta$ ) has been shown to destabilize iNOS message and protein in macrophages (52, $53)$ and vascular smooth muscle cells $(12,13)$, as well as inhibit cytokine-stimulated nitrite release from neonatal cardiac myocytes (43), we investigated whether TGF- $\beta$ could similarly reduce iNOS activity in adult rat cardiac myocytes and so reduce cytokine-induced NO-mediated autotoxicity. Simultaneous treatment of purified adult rat ventricular myocytes plated for $24 \mathrm{~h}$ with both TGF- $\beta$ and TNF- $\alpha$, IL- $1 \beta$, and IFN $\gamma$ resulted in markedly decreased expression of iNOS message (Fig. $3 \mathrm{~A}$, middle lane) and protein (Fig. 3 B, right lane). TGF- $\beta$ also had a remarkably obliterating effect on nitrite release from myocytes (both basal and cytokine-induced; Fig. $6 \mathrm{~A}$ ), which was associated with significantly less myocyte death in both the stimulated and unstimulated cardiac myocytes (Fig. 5, and Fig. 6, $B$ and $C)$. In fact, there was a tendency of TGF- $\beta$ to be protective even in the absence of cytokine stimulation (the lowest rates of myocyte death [32\% at $24 \mathrm{~h}$ after plating] were observed with TGF- $\beta$ treatment).

\section{Discussion}

Although immune mechanisms of cardiac disease has been the focus of much recent interest $(1,2)$, there has been little emphasis on the role of macrophages or NO as mediators of cardiac myocyte necrosis. Infiltrating macrophages, however, are found in abundance within the heart in a variety of cardiac diseases, including primary idiopathic myocarditis (37), the healing phases of myocardial infarction (36), and cardiac allograft rejection $(1,35,38)$ (where they comprise nearly $40 \%$ of the infiltrating cells) (54). We examined whether NO produced by cytokine-stimulated macrophages could act in a paracrine fashion to kill adjacent cardiac myocytes. These experiments demonstrated that induction of iNOS message, protein, and enzyme activity (assessed as nitrite production) in $\mathrm{J} 774$ macrophages paralleled killing of adjacent myocytes by a diffusible mediator. Because both nitrite production and myocyte death were reduced to background levels by inclusion of L-NMMA into the growth me- 

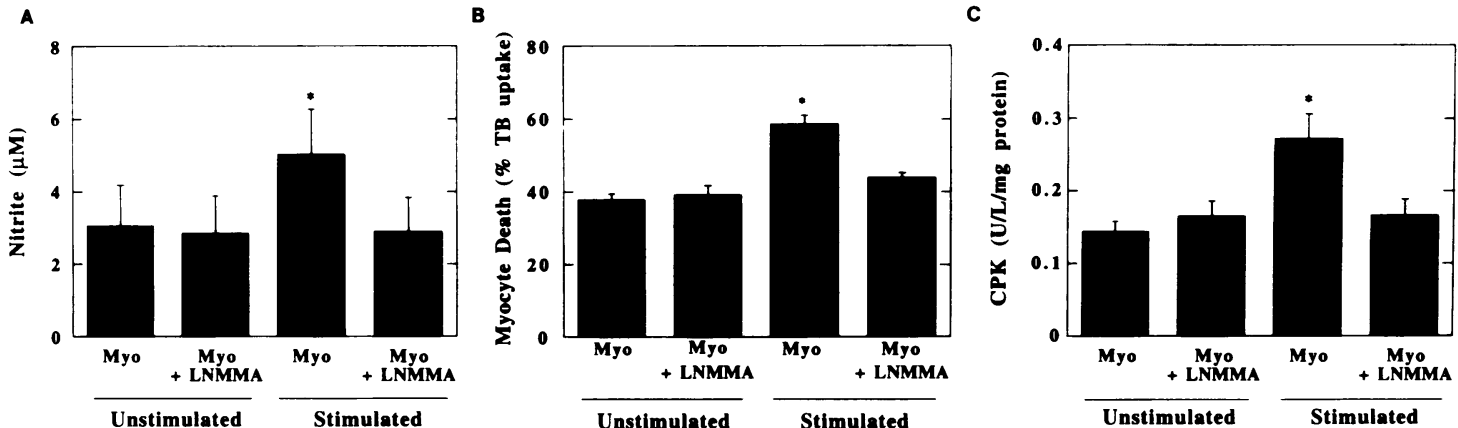

Figure 4. Effects of cytokine treatment on cardiac myocyte nitric oxide synthesis and death. Experiments were performed as described in Fig. 2 , except that these experiments were performed in the absence of macrophages. IFN $-\gamma$, tumor necrosis factor- $\alpha$, and interleukin 1- $\beta$ were used for stimulating myocyte iNOS expression where indicated. $(A)$ Nitrite was measured as an index of nitric oxide synthesis and $(B)$ trypan blue exclusion and $(C)$ CPK release were used to quantify myocyte death. Adult rat ventricular myocytes express iNOS activity (increased nitrite production) after cytokine treatment. which coincides with the expression of iNOS message and protein (Fig. 3) and myocyte cell death $(B$ and $C$ ). Addition of the competitive NO synthase inhibitor L-NMMA inhibits nitric oxide synthesis and myocyte death in parallel. Experiments for $(A-C)$ were performed in 24-well tissue culture dishes and represent data from experiments performed on three separate weeks, analyzed by repeated measures ANOVA $(* P<0.05$ vs. unstimulated controls).

dium, the data strongly suggests that myocyte killing was mediated by nitric oxide. As the doses of IFN- $\gamma$ and lipopolysaccharide selected to activate the macrophages did not induce iNOS activity in the target myocytes, this indicates that the source of the cytotoxic nitric oxide in the coculture experiments was the macrophages.

It is not surprising that NO secreted paracellularly may have important effects on cardiac myocytes that do not require direct cell contact, as NO produced by endothelial cells depresses the contractility of myocytes in coculture (32). Because NOmediated toxicity is not allospecific, and the cytokine rich mileu in allograft rejection (3) may induce macrophage iNOS expression (35), it is likely that macrophage-derived NO plays an important role in the myocyte necrosis which accompanies allo-
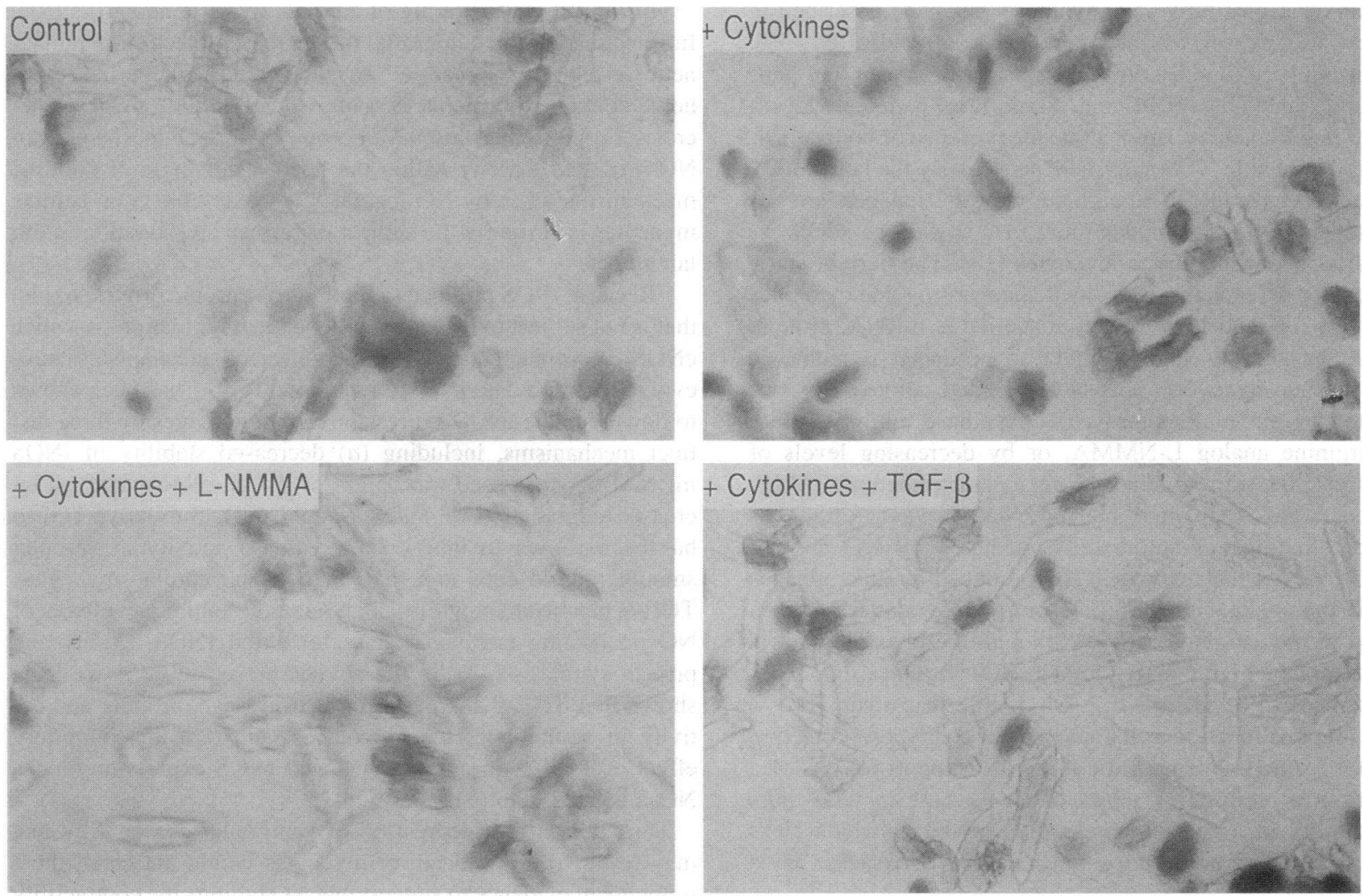

Figure 5. Representative trypan blue staining of adult rat ventricular myocytes. Myocytes were treated for $24 \mathrm{~h}$ with IFN- $\gamma$, TNF- $\alpha$, and interleukin $1-\beta(+(y$ tokines) in the presence of L-NMMA or TGF- $\beta$. or left untreated (control). Dead myocytes fail to exclude trypan blue and stain darkly, especially when cytokines are applied in the absence of L-NMMA or TGF- $\beta . \times 160$. 

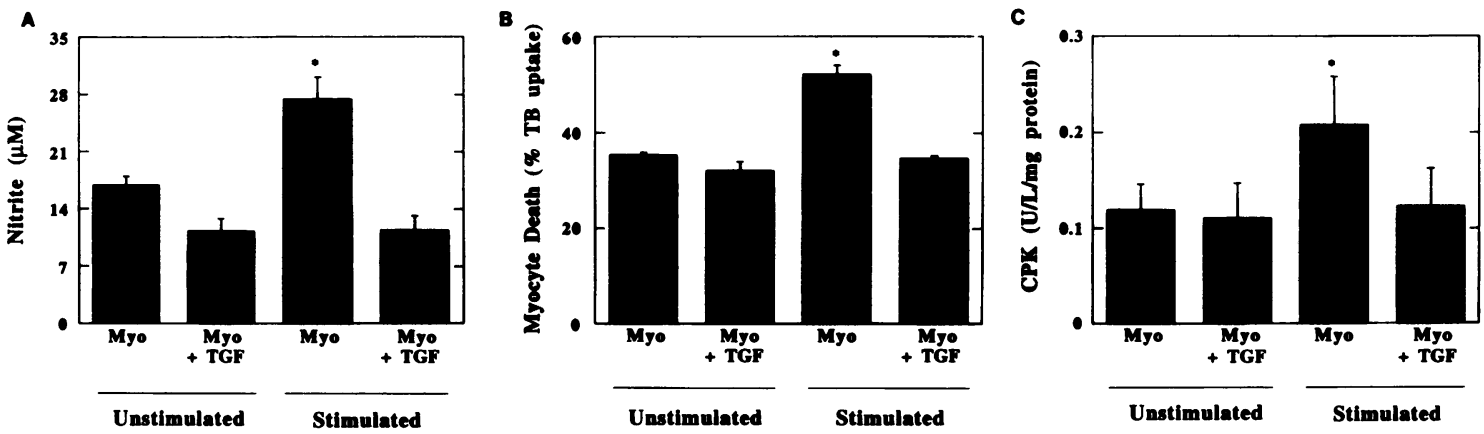

Figure 6. Effect of TGF- $\beta$ on cardiac myocyte iNOS activity and cell death. Experiments were performed as described in Fig. 4, except that TGF$\beta$ was used instead of L-NMMA. TGF- $\beta$ markedly attenuates nitrite accumulation $(A)$ as well as iNOS mRNA induction and protein expression (Fig. 3). TGF- $\beta$-induced reduction of cardiac myocyte iNOS mRNA, protein, and activity correspond to a protection against myocyte death as measured by trypan blue exclusion $(B)$ and CPK release $(C)$. Experiments for $A-C$ were performed in 24-well tissue culture dishes and represent data from experiments performed on three separate weeks, analyzed by repeated measures ANOVA $(* P<0.05$ vs. unstimulated controls).

graft rejection. This concept is supported by data which demonstrates the presence of iron-nitrosyl electron paramagnetic resonance signals (characteristic of NO) (55), increased nitric oxide synthase activity, and abundant iNOS-expressing macrophages in rejecting rat cardiac allografts (35). The paracrine toxic effects of NO produced by activated macrophages adjacent to cardiac myocytes may be similar to those responsible for tumor target cell (20-22), pancreatic islet $(23-25)$, ovarian epithelial cell (28), and hepatocyte (29) NO-mediated cytotoxicity.

The second set of experiments was designed to determine whether NO produced by iNOS within cardiac myocytes might be autotoxic. Constitutive NO synthesis has been described in the endocardium $(56,57)$ and coronary vasculature $(57-59)$, where it is likely to subserve important vasorelaxant and antithrombotic functions. Ventricular tissue from patients with dilated cardiomyopathies demonstrate the presence of both constitutive and inducible NOS activities (particularly the latter) (60). Other studies have identified high output, $\mathrm{Ca}^{2+}$-independent NO synthase activity in the myocardium (41) as well as iNOS expression in neonatal cardiac myocytes (18). The current study confirms and extends this work by demonstrating that cytokines (TNF- $\alpha$, IL- $1 \beta$, and IFN- $\gamma$ ) can induce iNOS mRNA, protein, and enzyme activity, and that NO so produced is autotoxic to the cardiac myocytes. This NO-mediated autotoxicity was prevented by either competitive NO synthase inhibition with the L-arginine analog L-NMMA, or by decreasing levels of iNOS transcripts and protein by coincident application of TGF$\beta$ with the cytokines which induced iNOS.

These findings of autotoxicity mediated by NO are not unique to ventricular myocytes. NO produced by macrophages (61) and endothelial cells (61) in response to cytokines has been reported to induce autotoxicity. Although the physiologic role of iNOS (and its highly toxic product, NO) within cardiac myocytes remains to be identified, it is possible that it subserves a similar immune function as it does in other cell types, protecting myocytes from viral or parasitic invasion. Support for this idea stems from a preliminary report of an increase in viral titers and mortality in a murine myocarditis model in which NOS inhibitors were given to mice infected with Coxsackie virus B3(62).

It is not surprising that nitric oxide is potentially toxic to cardiac myocytes. iNOS plays a critical microbicidal role, subserving important anti-bacterial $(6,8)$, anti-rickettsial $(63)$, anti- parasitic $(17,19)$, and anti-viral functions $(62,64,65)$, and may also be involved in the host response to tumor cells (20-22). There are many potential mechanisms by which nitric oxide may mediate its toxic effects on cardiac myocytes. By analogy with other descriptions of NO-mediated cytotoxicity, these may include auto-ADP-ribosylation of glycolytic enzymes (66), inhibition of ribonucleotide reductase (22), activation of poly (ADPribose) synthetase (26), inhibition of enzymes involved in the mitochondrial repiratory chain by the formation of iron-nitrosyl complexes $(21,55,67,68)$, inhibition of the citric acid cycle enzyme aconitase (25), formation of toxic species such as peroxynitrite (9), or triggering of cardiac myocyte apoptosis (61). In rejecting cardiac allografts, the increased electron paramagnetic resonance "signature" of NO bound to heme and nonheme containing proteins (55) in association with myocyte necrosis suggests that this may be one important mechanism of NO-mediated toxicity within the heart. The single or multiple mechanisms whereby NO mediates its toxic effects on cardiac myocytes is currently the subject of further investigation in our laboratory.

Because iNOS produces a highly toxic product (nitric oxide) that is not subject to the calcium-dependent regulation (to which cNOS is subject) $(9-11,14)$, powerful mechanisms have evolved to modulate iNOS expression. TGF- $\beta$ has been shown to downregulate iNOS expression in macrophages by three distinct mechanisms, including (a) decreased stability of iNOS mRNA; $(b)$ decreased translation of iNOS mRNA; and $(c)$ increased degradation of iNOS protein (53). Similarly, TGF- $\beta$ has been shown to inhibit NO synthase activity in vascular smooth muscle cells $(12,13)$. In neonatal cardiac myocytes, TGF- $\beta$ has been shown to antagonize the inhibitory effects of NO on beating rate, as well as to inhibit iNOS activity and protein synthesis (43). In the studies presented here, we have shown that TGF- $\beta$ suppresses iNOS message, protein, and activity in adult rat cardiac myocytes, and that this inhibitory effect of TGF- $\beta$ on cytokine-induced iNOS expression blocks NO-mediated autotoxicity.

In addition to a depression of ventricular contractility that may result from the death of myocytes within the heart, there is abundant evidence to suggest that NO inhibits the contractility and beating rate of cardiac myocytes (30-34). Myocardial contractility can be profoundly impaired by conditions associated with elevated levels of local or circulating cytokines, including 
viral myocarditis, cardiac allograft rejection, and sepsis $(35$, 69-73). Supernatants from activated mononuclear cells (74) and the proinflammatory cytokines TNF $\alpha$ and IL-1 $\beta(75,76)$ have negative inotropic effects on cardiac myocytes in culture as well as in isolated beating hearts (72). NO produced by either constitutive or inducible NOS within rat heart muscle cells inhibits the positive inotropic effects of beta adrenergic agonists (31), and exogenous administration of NO or iNOS induction by endotoxin administration impairs the contractility of guinea pig cardiac myocytes (32). Recent work has delineated a role for cytokine-induced NO synthesis in the negative inotropic effects observed following cytokine administration (30-32, 34), probably mediated by cGMP (77-79). These observations, as well as data from the current study confirming endogenous cardiac production of nitric oxide, suggest that nitric oxide may also depress myocardial contractility independent of myocyte killing.

The finding that cytokines themselves induce myocyte autotoxicity without the requirement for adjacent NO-producing cells may be especially relevant for those conditions associated with elevated circulating levels of cytokines without a notable inflammatory infiltrate $(4,5,80-83)$. This is potentially very relevant to the pathophysiology of various cardiac disease states, including the inexorable progression of end-stage heart failure, which has been associated with elevated circulating levels of TNF $(4,5)$, as well as cardiac allograft rejection, in which a multitude of cytokines are expressed in the local milieu (3). In addition, nearly one fifth of all cases of dilated cardiomyopathy are associated with a nonspecific myocarditis characterized by an inflammatory infiltrate (37), also suggesting the local presence of a cytokine-rich milieu. In addition to these observations, case reports of cytokine-induced cardiac toxicity leading to irreversible cardiomyopathy abound $(37,80-83)$, with infusions of IFN- $\alpha$, TNF- $\alpha$, or IL- 2 implicated as offending agents. One recent trial demonstrated a survival benefit in patients with heart failure treated with a therapy (84) which has potent anti-cytokine properties as a major side effect (85). The identification of elevated cardiac iNOS activity in patients with dilated cardiomyopathy (60) and confirmation of recombinant-cytokine induced NO production in man (86) further support the potential clinical relevance of these observations.

Taken together, these experiments demonstrate that NO is potentially cardiotoxic, whether it is produced by adjacent inflammatory cells or by cardiac myocytes themselves exposed to a cytokine-rich mileu. These findings may help explain the inexorable progression and demise of many patients with cardiomyopathies of diverse etiologies, and suggest potential therapeutic strategies to limit ongoing myocardial damage in transient high cytokine states, including sepsis, anti-tumor therapy with recombinant cytokines, cardiac allograft rejection, infarction, and myocarditis. These studies raise the possibility that NO-mediated cytotoxicity represents a final common pathway for the myocardial damage caused by proinflammatory cytokines or inflammatory cellular infiltrates, and that blocking iNOS expression or activity may be of potential therapeutic benefit.

\section{Acknowledgments}

We thank B. Cai for carrying out most of the experiments described in the results section. D. Pinsky is a Clinician-Scientist of the American Heart Association.
This work was supported in part by the Public Health Service (HL21006) and a Grant-in-Aid from the American Heart Association.

\section{References}

1. Barry, W. H. 1994. Mechanisms of immune-mediated myocyte injury. Circulation. 89 (5):2421-2432.

2. Lange, L. G., and G. F. Schreiner. 1994. Immune mechanisms of cardiac disease. N. Engl. J. Med. 330 (16):1129-1135.

3. Dallman, M. J., C. P. Larsen, and P. J. Morris. 1991. Cytokine gene transcription in vascularised organ grafts: analysis using semiquantitative polymerase chain reaction. J. Exp. Med. 174:493-496.

4. Levine, B., J. Kalman, L. Mayer, H. M. Fillit, and M. Packer. 1990. Elevated levels of tumor necrosis factor in severe chronic heart failure. N. Engl. J. Med. 323:236-241.

5. Katz, S. D., R. Rao, J. W. Berman, M. Schwarz, L. Demopoulis, R. Bijou, and T. H. LeJemtel. 1994. Pathophysiological correlates of increased serum tumor necrosis factor in patients with congestive heart failure: relation to nitric oxidedependent vasodilation in the forearm circulation. Circulation. 90:12-16.

6. Xie Q-w, H. J. Cho, J. Calaycay, R. A. Mumford, K. M. Swiderek, T. D. Lee, A. Ding, T. Troso, and C. Nathan. 1992. Cloning and characterization of inducible nitric oxide synthase from mouse macrophages. Science (Wash. DC). 256:225-228.

7. Stuehr, D. J., and M. A. Marletta. 1985. Mammalian nitrate biosynthesis: mouse macrophages produce nitrite and nitrate in response to escherichia coli lipopolysaccharide. Proc. Natl. Acad. Sci. USA. 82:7738-7742.

8. Drapier, J. C., J. Weizesbin, and J. B. Hibbs. 1988. Interferon g and tumor necrosis factor induce the L-arginine-dependent cytotoxic effects or mechanism in murine macrophages. Eur. J. Immunol. 18:1587-1592.

9. Moncada, S. 1992. The L-arginine:nitric oxide pathway. Acta Physiol. Scand. 145:201:227.

10. Ignarro, L. J. 1990. Biosynthesis and metabolism of endothelium-derived nitric oxide. Ann. Rev. Toxicol. 30:535-560.

11. Lowenstein, C., and S. Snyder. 1992. Nitric oxide, a novel biologic messenger. Cell. 70:705-707.

12. Schini, V. B., W. Durante, E. Elizondo, T. Scott-Burden, D. C. Junquero, A. I. Schafer, and P. M. Vanhoutte. 1992. The induction of nitric oxide synthase activity is inhibited by TGF- $\beta_{1}$, PDGF $_{\mathrm{AB}}$, and PDGF $\mathrm{BB}_{\mathrm{BB}}$ in vascular smooth muscle cells. Eur. J. Pharmacol. 216:379-383.

13. Junquero, D. C., T. Scott-Burden, V. B. Schini, and P. M. Vanhoutte Inhibition of cytokine-induced nitric oxide production by transforming growth factor $\beta 1$ in human smooth muscle cells. 1992. J. Physiol. 454:451-465.

14. Forstermann, U., M. Nakane, W. R. Tracey, and J. S. Pollock. 1993 Isoforms of nitric oxide synthase: functions in the cardiovascular system. Eur. Heart J. 14 (suppl.I):10-15.

15. Geng, Y., G. K. Hansson, and E. Holme. 1992. Interferon-gamma and tumor necrosis factor synergize to induce nitric oxide production and inhibit mitochondrial respiration in vascular smooth muscle cells. Circ. Res. 71(5):12681276.

16. Estrada, C., C. Gomez, C. Martin, S. Moncada, and C. Gonzalez. 1992. Nitric oxide mediates tumor necrosis factor-alpha cytotoxicity in endothelial cells. Biochem. Biophys. Res. Commun. 186(1):475-482.

17. Oswald, I. P., I. Eltoum, T. A. Wynn, B. Scwartz, P. Caspar, D. Paulin, A. Sher, and S. L. James. 1994. Endothelial cells are activated by cytokine treatment to kill an intravascular parasite, Schistosoma mansoni, through the production of nitric oxide. Proc. Natl. Acad. Sci. USA. 91(3):999-1003.

18. Tsujino, M., Y. Hirata, T. Imai, K. Kanno, S. Eguchi, H. Ito, and F. Marumo. 1994. Induction of nitric oxide synthase gene by Interleukin- $1 \beta$ in cultured rat cardiocytes. Circulation. 90:375-383.

19. Gazzinelli, R. T., I. P. Oswald, S. Hieny, S. L. James, and A. Sher. 1992 The microbicidal activity of interferon- $\gamma$-treated macrophages against Trypanosoma cruzi involves an L-arginine-dependent, nitrogen oxide-mediated mechanism inhibitable by interleukin-10 and transforming growth factor- $\beta$. Eur. $J$. Immunol. 22:2501-2506.

20. Stuehr, D. J., and C. Nathan. 1989. Nitric oxide: a macrophage product responsible for cytostasis and respiratory inhibition in tumor target cells. $J$. Exp. Med. 169:1543-1555.

21. Drapier, J. C., C. Pellat, and Y. Henry. 1991. Generation of EPR-detectable nitrosyl-iron complexes in tumor target cells cocultured with activated macrophages. J. Biol. Chem. 266:10162-10167.

22. Kwon, N. S., D. J. Stuehr, and C. F. Nathan. 1991. Inhibition of tumor cell ribonucleotide reductase by macrophage-derived nitric oxide. J. Exp. Med. 174(4):761-767.

23. Kroncke, K. D., V. Kolb-Bachofen, B. Berschick, V. Burkan, and H. Kolb. 1991. Activated macrophages kill pancreatic syngeneic islet cells in argininedependent nitric oxide generation. Biochem. Biophys. Res. Commun. 175:752758.

24. Corbett, J. A., J. L. Wang, T. P. Misko, W. Zhao, W. F. Hickey, and 
M. L. McDaniel. 1993. Nitric oxide mediates IL-1 beta-induced islet dysfunction and destruction: prevention by dexamethasone. Autoimmunity. 15(2):145-153.

25. Welsh, N., and S. Sandler. 1992. Interleukin-1 beta induces nitric oxide production and inhibits the activity of aconitase without decreasing glucose oxidation rates in isolated pancreatic islets. Biochem. Biophys. Res. Commun. 182(1):333-340.

26. Zhang, J., V. L. Dawson, and T. M. Danson. 1994. Nitric oxide activation of poly(ADP-ribose) synthetase in neurotoxicity. Science (Wash. DC). 263: 687689.

27. Dawson, T. M., V. L. Dawson, and S. H. Snyder. 1992. A novel neuronal messenger molecule in brain: the free radical, nitric oxide. Ann. Neurol. 32:297311 .

28. Ellman, C., J. A. Corbett, T. P. Misko, M. McDaniel, and K. P. Beckerman. 1993. Nitric oxide mediates interleukin-1-induced cellular cytotoxicity in the rat ovary. A potential role for nitric oxide in the ovulatory process. J. Clin. Invest. 92(6):3053-3056

29. Billiar, T R R D Curran, D. J Stuehr, M. A. West, B. G. Bentz, and R. L. Simmons. 1989. An L-arginine-dependent mechanism mediates Kupfer cell inhibition of hepatocyte protein synthesis in vitro. J. Exp. Med. 169:1467-1472.

30. Finkel, M. S., C. V. Oddis, T. D. Jacob, S. C. Watkins, B. G. Hattler, and R. L. Simmons. 1992. Negative inotropic effects of cytokines on the heart mediated by nitric oxide, Science (Wash. DC). 257:387-389.

31. Balligand, J.-L., D. Ungureanu, R. A. Kelly, L. Kobzik, D. Pimental, T. Michel, and T. W. Smith. 1993. Abnormal contractile function due to induction of nitric oxide synthesis in rat cardiac myocytes follows exposure to activated macrophage-conditioned medium. J. Clin. Invest. 91:2314-2319.

32. Brady, A. J., J. B. Warren, P. A. Poole-Wilson, T. J. Williams, and S. E. Harding. 1993. Nitric oxide attenuates cardiac myocyte contraction, Am. J. Physiol. 265(34):H176-H182.

33. Balligand, J.-L., R. A. Kelly, P. A. Marsden, T. W. Smith, and T. Michel, Control of cardiac muscle cell function by an endogenous nitric oxide signalling system. 1993. Proc. Natl. Acad. Sci. USA. 90:347-351.

34. Brady, A. J. B., P. A. Poole-Wilson, S. E. Harding, and J. B. Warren. 1992. Nitric oxide production within cardiac myocytes reduces their contractility in endotoxemia. Am. J. Physiol. 263:H1963-1966.

35. Yang, X., N. Chowdhury, B. Cai, J. Brett, C. Marboe, R. R. Sciacca, R. E. Michler, and P. J. Cannon. 1994. Induction of myocardial nitric oxide synthase by cardiac allograft rejection. J. Clin. Invest. 94:714-721.

36. Edwards, W. D. 1991. Pathology of myocardial infarction and reperfusion. In Acute Myocardial Infarction. B. J. Gersh and S. H. Rahimtoola, editors, Elsevier, New York. p. 24

37. Kasper, E. K., W. R. P. Agema, G. M. Hutchins, J. W. Deckers, J. M. Hare, and K. L. Baughman. 1994. The causes of dilated cardiomyopathy: a clinicopathologic review of 673 consecutive patients. J. Am. Coll. Cardiol. 23(3):586590.

38. Marboe, C. C., S. W. Schierman, E. Rose, K. Reemtsma, and J. J. Fenoglio. 1984. Characterization of mononuclear cell infiltrates in human cardiac allografts. Transplant Proc. 16:1598-1599.

39. Langrehr, J. M., D. A.White, R. A. Hoffman, and R. L. Simmons. 1993. Macrophages produce nitric oxide at allograft sites. Ann. Surg. 218(2):159-166.

40. Langrehr, J. M., R. L. Simmons, and R. A. Hoffman. 1992. Graft-infiltrating cell nitric oxide production is stimulated by TNF alpha. Transplant Proc. 24(6):2893.

41. Schulz, R. E., E. Nava, and S. Moncada. 1992. Induction and potential biological relevance of a $\mathrm{Ca}^{2+}$-independent nitric oxide synthase in the myocardium. Br. J. Pharmacol. 105:575-580.

42. Balligand, J.-L., D. Ungureanu, D. Pimental, R. A. Kelly, T. W. Smith, and $T$. Michel 1993. Detection of transcripts for a cytokine inducible nitric synthase isoform in adult rat ventricular myocytes. Circulation. 88 (4 pt 2):I384. (Abstr.)

43. Roberts, A. B., Y. Vodovotz, N. S. Roche, M. B. Sporn, and C. F. Nathan. 1992. Role of nitric oxide in antagonistic effects of transforming growth factor$\mathrm{B}$ and interleukin $1-\beta$ on the beating rate of cultured cardiac myocytes. Mol. Endocrinol. 6:1921-1930.

44. Wittenberg, B. A., and T. F. Robinson. 1981. Oxygen requirements, morphology, cell coat and membrane permeability of calcium tolerant myocytes from hearts of adult rats. Cell Tissue Res. 216:231-251.

45. Osbakken, M., T. Ivanic, D. Zhang, R. Mitza, and H. Blum. 1992. Isolated cardiomyocytes in conjunction with NMR spectroscopy techniques to study metabolism and ion flux. J. Biol. Chem. 267:15340-15347.

46. Vincent, R., and D. Nadeau. 1984. Adjustment of the osmolality of percol for the isopycnic separation of cells and cell organelles. Anal. Biochem. 141:322328.

47. Yang, X., B. Cai, R. R. Sciacca, and P. J. Cannon. 1994. Inhibition of inducible nitric oxide synthase in macrophages by oxidized low-density lipoproteins. Circ. Res. 74:318-328.

48. Lowry, O., N. Rosebrough, A. Farr, and R. Randall. 1951. Protein measurement with the Folin reagent. J. Biol. Chem. 193:265-275.

49. Green, L. C., D. A. Wagner, J. Glogowski, P. L. Skipper, J. S. Wishnok, and S. R. Tannenbaum. 1982. Analysis of nitrate, nitrite, and $\left[{ }^{15} \mathrm{~N}\right]$ nitrate in biological fluids. Anal. Biochem. 126:131-138.

50. Chomozynski, P., and N. Sacchi. 1987. Single step method of RNA induction by acid guanidinium-thiocyanate-phenol-chloroform extraction. Anal. Biochem. 162:156-159.

51. Lorsbach, R. B., W. J. Murphy, C. J. Lowenstein, S. H. Snyder, and S. W. Russel. 1993. Expression of the nitric oxide synthase gene in mouse macrophages activated for tumor cell killing. Molecular basis for the synergy between interferon-gamma and lipopolysaccharide. J. Biol. Chem. 268(3):1908-1913.

52. Bogdan, C., J. Paik, Y. Vodovotz, and C. Nathan. 1992. Contrasting mechanisms for suppression of macrophage cytokine release by transforming growth factor- $\beta$ and interleukin-10. J. Biol. Chem. 267(22):23301-23308.

53. Vodovotz, Y., C. Bogdan, J. Paik, Q.-W. Xie, and C. Nathan. 1993. Mechanisms of suppression of macrophage nitric oxide release by transforming growth factor $\beta$. J. Exp. Med. 17X:605-613.

54. Strom, T. B., N. L. Tilney, J. M. Paradysz, J. Bancewicz, and C. B. Carpenter. 1977. Cellular components of allograft rejection: identity, specificity, and cytotoxic functions of cells infiltrating acutely rejecting allografts. J. Immunol. 118:2020-2026.

55. Lancaster, J. R., Jr., J. M. Langehr, H. A. Bergonia, N. Murase, R. L. Simmons, and R. A. Hoffman. 1992. EPR detection of heme and non-heme iron-containing protein nitrosylation by nitric oxide during rejection of rat heart allograft. J. Biol. Chem. 267(16):10994-10998.

56. Schulz, R., J. A. Smith, M. J. Lewis, and S. Moncada. 1991. Nitric oxide synthase in cultured endocardial cells of the pig. Br. J. Pharmacol. 104:21-24.

57. Pinsky, D. J., M. C. Oz, S. Koga, Z.Taha, M. J. Broekman, A. J. Marcus, H. Liao, Y. Naka, J. Brett, P. J. Cannon, R. Nowygrod, T. Malinski, and D. M. Stern. 1994. Cardiac preservation is enhanced in a hetertopic rat transplant model by supplementing the nitric oxide pathway. J. Clin. Invest. 93:2291-2297.

58. Schrader, J., and M. Kelm. 1990. Control of coronary vascular tone by nitric oxide. Circ. Res. 66:1561-1575.

59. Amrani, M., J. O'Shea, N. J. Allen, S. E. Harding, J. Jayakuma, J. R. Pepper, S. Moncada, and M. H. Yacoub. 1992. Role of basal release of nitric oxide on coronary flow and mechanical performance of the isolated rat heart, $J$. Physiol. 456:681-687.

60. DeBelder, A. J., M. W. Radomski, H. J. F. Why, P. J. Richardson, C. A Bucknall, E. Salas, J. F. Martin, and S. Moncada. 1993. Nitric oxide synthase activities in human myocardium. Lancet. 341:84-85.

61. Albina, J. E., S. Cui, R. B. Mateo, and J. S. Rerichner. 1993. Nitric oxidemediated apoptosis in murine peritoneal macrophages. J. Immunol. 150(11):50805085.

62. Lowenstein, C., G. Allen, A. Walker, N. Rose, S. Snyder, and A. Herskowitz. 1993. Nitric oxide inhibits viral replication in myocarditis. Circulation. 88(4, pt. 2):IG-IH. (Abstr).

63. Feng, H.M., and D. H. Walker. 1993. Interferon-gamma and tumor necrosis factor alpha exert their antirickettsial effect via induction of synthesis of nitric oxide. Am. J. Pathol. 143(4):1016-1023.

64. Kurapiah, G., Q. W. Xia, R. M. Buller, C. Nathan, C. Duarte, and J. D. MacMicking. 1993. Inhibition of viral replication by interferon-gamma-induced nitric oxide synthase. Science (Wash. DC). 261(5127):1445-1448.

65. Croen, K. D. 1993. Evidence for antiviral effect of nitric oxide. Inhibition of herpes simplex virus type I replication. J. Clin. Invest. 91(6):2446-2452.

66. Dimmeler, S., M. Ankarcrona, P. Nicotera, and B. Brune. 1993. Exogenou nitric oxide (NO) generation or IL-1 beta-induced intracellular NO production stimulates inhibitory auto-ADP-ribosylation of glyceraldehyde-3-phosphate dehydrogenase in RINm5F cells. J. Immunol. 150(7):2964-2971.

67. Pellat, C., Y. Henry, and J. C. Drapier. 1990. IFN-gamma-activated macrophages: detection by electron paramagnetic resonance of complexes between $\mathrm{L}$ arginine-derived nitric oxide and non-heme iron proteins. Biochem. Biophys. Res. Commun. 166(1):119-125.

68. Lancaster, J. R., Jr., and J. B. Hibbs, Jr. 1990. EPR demonstration of ironnitrosyl complex formation by cytotoxic activated macrophages. Proc. Natl. Acad. Sci. USA. 87:1223-1227.

69. Solis, R. T., and S. E. Downing. 1966. Effects of E. coli endotoxemia on ventricular performance. Am. J. Physiol. 211:307-313.

70. Parrillo, J. E., C. Burch, J. H. Shelhamer, M. M. Parker, C. Natanson, and W. Schuette. 1985. A circulating myocardial depressant substance in humans with septic shock: septic shock patients with reduced ejection fraction have a circulating factor that depresses in vitro myocardial performance. J. Clin. Invest. 76:15391553

71. Suffredini, A. F., R. E. Fromm, M. M. Parker, M. Brenner, J. A. Kovacs, R. A. Wesley, and J. E. Parrillo. 1989. The cardiovascular response of normal humans to the administration of endotoxin. N. Engl. J. Med. 321:280-287.

72. Sobotka, P.A., J. McMannis, R. I. Fisher, D. G. Stein, and J. X. Thomas, Jr. 1990. Effects of interleukin-2 on cardiac function in the isolated rat heart. $J$. Clin. Invest. 86(3):845-850.

73. Abel, F. L. 1990. Does the heart fail in endotoxin shock? Circ. Shock $30: 5-13$ 
74. Chung, M. K., T. S. Gulick, R. E. Rotondo, G. F. Schreiner, and L. G. Lange. 1990. Mechanism of cytokine inhibition of $\beta$-adrenergic agonist stimulation of cyclic AMP in rat cardiac myocytes. Circ. Res. 67:753-763.

75. Gulick, T., M. K. Chung, S. J. Pieper, L. G. Lange, and G. F. Schreiner 1989. Interleukin- 1 and tumor necrosis factor inhibit cardiac myocyte $\beta$ adrenergic responsiveness. Proc. Natl. Acad Sci. USA. 86:6753-6757.

76. Gulick, T., S. J. Pieper, M. A. Murphy, L. G. Lange, and G. F. Schreiner 1991. A new method for assessment of cultured cardiac myocyte contractility detects immune factor-mediated inhibition of $\beta$-adrenergic responses. Circulation. 84:313-321.

77. Nawroth, H. 1977. Does cGMP mediate the negative inotropic effect of acetylcholine in the heart? Nature (Lond.). 267:72-74.

78. Shah, A. M., M. J. Lewis, and A. H. Henderson. 1991. Effects of 8Bromo-cyclic GMP on contraction and on inotropic response of ferret cardiac muscle. J. Mol. Cell. Cardiol. 23:55-64.

79. Shah, A. M., H. A. Spurgeon, S. J. Sollott, A. Talo, and E. G. Lakatta 1994. 8-Bromo cGMP reduces the myofilament response to calcium in intact cardiac myocytes. Circ. Res. 74:970-978.

80. Nora, R., J. S. Abrams, N. S. Tait, D. J. Hipponia, and H. J. Silverman.
1989. Myocardial toxic effects during recombinant interleukin-2 therapy. J. Natl. Cancer Inst. 81:59-63.

81. Osanto, S., F. H. M. Cluitmans, C. R. Franks, et. al. 1988. Myocardia injury after interleukin-2 therapy. Lancet. 2:48-49.

82. Hegewish, S., H.-J. Weh, and D. K. Hossfeld. 1990. TNF-induced cardiomyopathy. Lancet. 2:294-295.

83. Cohen, M. C., M. S. Huberman, and R. W. Nestro. 1988. Recombinant alpha-2 interferon related cardiomyopathy. Am. J. Med. 85:549-551.

84. Feldman, A. M., M. R. Bristow, W. W. Parmley, P. E. Carson, C. J. Pepine, E. M. Gilbert, J. E. Strobeck, G. H. Hendrix, E. R. Powers, R. P. Bain, and B. G. White. Effects of vesnarinone on morbidity and mortality in patients with heart failure. 1993. N. Engl. J. Med. 329:149-155.

85. Matsumori, A., S. Tetsuo, T. Yamada, S. Matsui, and S. Sasayama. 1994 Vesnarinone, a new inotropic agent, inhibits cytokine production by stimulated human blood from patients with heart failure. Circulation. 89(3):955-958.

86. Hibbs, J. B., C. Westenfelder, R. Taintor, Z. Vavrin, C. Kablitz, R. L. Baranowski, J. H. Ward, R. L. Menlove, M. P. McMurry, J. P. Kushner, and W. E. Samlowski. 1992. Evidence for cytokine-inducible nitric oxide synthesis from L-arginine in patients receiving interleukin-2 therapy. J. Clin. Invest. 89: 867-877. 